\title{
The Impact of Social Influence, Technophobia, and Perceived Safety on Autonomous Vehicle Technology Adoption
}

\author{
Sahil Koul ${ }^{1 *}$, Ali Eydgahi \\ ${ }^{1}$ College of Technology, Eastern Michigan University, Ypsilanti, Michigan, 48197, USA \\ 2 School of Engineering Technology, Eastern Michigan University, Ypsilanti, Michigan, 48197, USA \\ ${ }^{*}$ Corresponding author, e-mail: skoul@emich.edu
}

Received: 01 August 2017, Accepted: 09 July 2018, Published online: 16 April 2019

\begin{abstract}
The objective of this study was to determine whether there was a relationship between social influence, technophobia, perceived safety of autonomous vehicle technology, number of automobile-related accidents and the intention to use autonomous vehicles. The methodology was a descriptive, cross-sectional, correlational study. Theory of Planned Behavior provided the underlying theoretical framework. An online survey was the primary method of data collection. Pearson's correlation and multiple linear regression were used for data analysis. This study found that both social influence and perceived safety of autonomous vehicle technology had significant, positive relationships with the intention to use autonomous vehicles. Additionally, a significant negative relationship was found among technophobia and intention to use autonomous vehicles. However, no relationship was found between the number of automobilerelated accidents and intention to use autonomous vehicles. This study presents several original and significant findings as a contribution to the literature on autonomous vehicle technology adoption and proposes new dimensions of future research within this emerging field. Keywords

theory of planned behavior, autonomous vehicle technology, social influence, technophobia, perceived safety
\end{abstract}

\section{Introduction}

Autonomous vehicle technology (AVT) could potentially revolutionize the global transportation industry (Bansal et al., 2016; Gadepally, 2013; Guerra, 2016; Lam et al., 2016; Talebpour and Mahmassani, 2016). Anticipating AVT adoption is critical for its success, and hence requires more comprehensive research and data collections in various settings (Bansal et al., 2016; Casley et al., 2013; Heide and Henning, 2006; Menon, 2015; Payre et al., 2014).

Much more research is needed to study the factors that may impact both short and long-term adoption of AVT (Nees, 2016). Consequently, researchers have conducted studies on multiple dimensions of this disruptive technology (Yibing et al., 2014; Tettamanti et al., 2016). Moreover, official planners are closely observing research on autonomous vehicles (AV), and they are keenly looking to comprehend and prepare for future impacts (Guerra, 2016). Consumer adoption decisions for AVT will likely vary within different demographics and geographies (Brett, 2016), and therefore highlighting significant factors will help effectively transition to our new transportation system (Bansal et al., 2016; Bansal et al., 2017).
National Highway Traffic Safety Administration (NHTSA, 2013) classifies vehicles into five different categories of automation in United States. NHTSA level four of automation includes completely self-driving vehicles, controlling all critical safety function without any input from its passengers. This level of automation has no driver.

This study examines the presence of any relationship between social influence, technophobia, perceived safety of AVT, and number of automobile-related accidents (independent constructs) and the intention to use AV (dependent construct) utilizing an automotive accessory manufacturer with 13 divisons located across the United States (U.S.). This study further examined the moderating effects of socio-economic demographic variables on the relationships as shown in Fig. 1.

\section{Literature review}

This section provides a concise review of the Theory of Planned Behavior as well as the constructs of social influence, technophobia, and the perceived safety of AVT. 


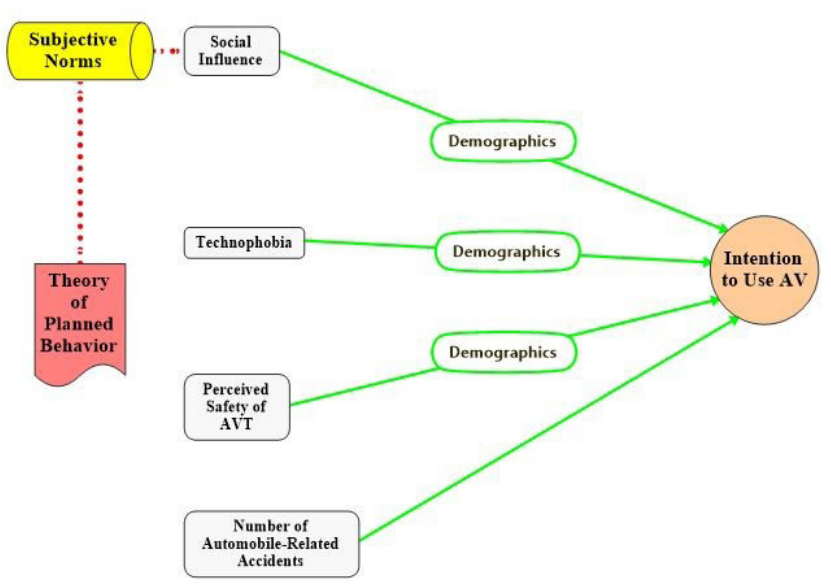

Fig. 1 Conceptual Framework.

\subsection{Theory of Planned Behavior}

The Theory of Planned Behavior (TPB; Ajzen, 1985; 1991) is still one of the best theories used in marketing research of individual's acceptance of a wide variety of technologies (Li, 2010). As shown in Fig. 2, this theory is comprised of three main constructs: Attitude, Subjective Norms, and Perceived Behavior Control, which in turn influences the individual's intention and then eventually behavior towards a particular act, process, product, or situation (Ajzen, 1985; 1991).

TPB predicts that positive attitude towards a behavior, favourable social norms, and a greater level of perceived behavioural control are indicators of forming strong behavioral intentions and vice versa (Ajzen and Fishbein, 2010; Bamberg et al., 2003).

From the utility standpoint, TPB has a variety of applications, including, but not limited to, driving violations (Parker et al., 1992), health (Godin and Kok, 1996), leisure (Ajzen and Driver, 1992), technology adoption (Taylor and Todd, 1995), choice of travel mode (Bamberg et al., 2003), internet purchasing (George, 2004), internet banking (Shih and Fang, 2004), and e-commerce adoption (Pavlou and Fygenson, 2006).

\subsection{Social influence}

An individual can generate interpersonal influences through many sources, such as friends, family, and other inspirational figures (Kulviwat et al., 2009). The subjective norm construct of TPB via social influence (SI) was used to describe the individual's perception of voluntary social pressure that ultimately triggers behavioral intention (Mathieson, 1991). SI is defined "as the degree to which an individual perceives that important others believe he or she should use the new system" (Venkatesh

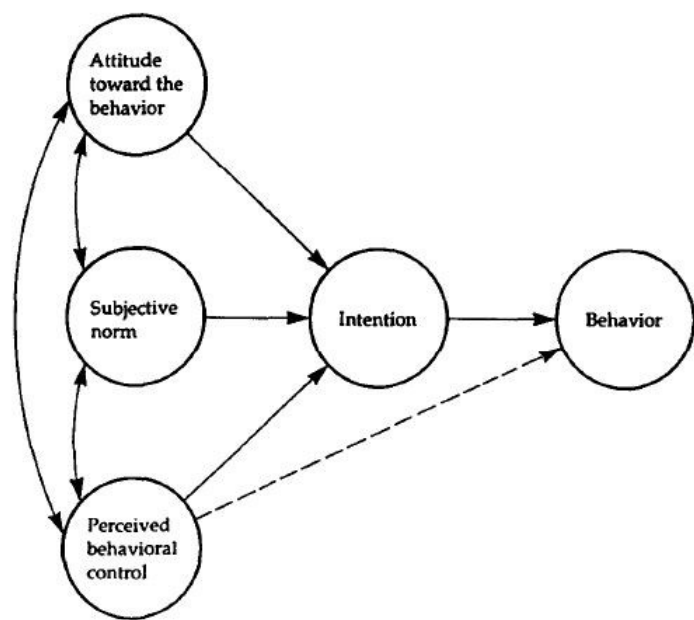

Fig. 2 Theory of Planned Behavior Model. (Adapted from Ajzen, 1991:p.182)

et al., 2003, p. 451). Lu et al. (2005) provided a similar definition of SI as perceived pressure generated via social network to decide on a certain behavior. The basic notion associated with SI is that an individual's behavior is influenced by the perception of important or relevant others' opinion (Holden and Karsh, 2010; Venkatesh et al., 2003).

Age and gender can be expected to moderate the relationship between SI and behavioral intentions (Venkatesh et al., 2003). SI has mixed results on user acceptance ( $\mathrm{Li}$, 2010), and researchers believe the inclusion of social influence remains to be explored by future studies in different settings (Lee et al., 2003). Bansal et al. (2016) suggested that autonomous vehicle adoption by friends and family may generate social pressure and increase self-confidence, prompting an individual to buy such technology.

\subsection{Technophobia}

With rapidly changing technology, many researchers have used a variety of approaches to assess human psychological reactions to technology through various constructs such as technostress, cyberphobia, and technophobia (Gilbert et al., 2003). However, the fusion of the two different constructs 'technophobia' and 'computer anxiety' has developed some strains of confusion in the scholarly community (Khasawneh, 2015). For the purpose of this study, technophobia is defined as "an irrational fear and/or anxiety that individuals form as a response to a new stimulus that comes in the form of a technology which modifies and/or changes the individual's normal or previous routine in performing a certain task" (Khasawneh, 2015, p.38).

The role of technophobia regarding innovation adoption remains relatively underexplored when compared to 
demographic variables, such as level of education, standard of living, and income levels (Sinkovics et al., 2002). Celaya (1996), estimated that $20 \%$ to $33 \%$ of people living in the U.S. could be classified as technophobes, which may potentially influence AV adoption, and this population is getting older. Age and gender can be expected to have a moderate correlation with technophobia (Gilbert et al., 2003). Also, Kulviwat et al. (2009) advised that technophobia, perceived benefits, and technology experience as related to individual characteristics be incorporated in future studies of innovation adoption. Although being technophobic is the opposite of technophobic behavior, it still serves the recommendation made by Payre et al. (2014) and is a reverse investigation.

\subsection{Perceived Safety of AVT}

Safety is providing the thrust behind the development of AVT, which may potentially reduce the frequency and severity of traffic-related crashes (Brett, 2016). The perceived safety of AVT was defined as the degree to which potential consumers perceive the level of safety associated with this technology (Casley et al., 2013).

During the first nine months of 2016, statistics by the NHTSA (2016) show that an estimated 27,875 fatalities occurred due to traffic-related crashes. Overall, traffic-related fatalities in 2016 increased by $8 \%$ compared to 2015 (NHTSA, 2016). The prevalence of young drivers involved in traffic crashes continues to remain a worldwide concern (Chen, 2016; Creaser, 2004; Dorn, 1992). If these crashes are not reduced, it is estimated that vehicle accidents could become the fifth most prominent reason for human death globally (Chen, 2016).

Fagnant and Kockelman (2015) estimated a 40 \% reduction in the fatal crash rate by utilizing AVT. The advocates of AVT argue that AV increases the safety of passengers and surroundings by reducing crash-related errors and mitigating risks associated with impaired driving (Litman, 2014). Therefore, the notion of perceived safety of AVT becomes a significant factor that may influence consumers' behavioral intentions to use AV.

Autonomous vehicles liability issues are also getting increased attention. Although liability is an important issue with respect to motor vehicle operation, but automation dramatically increase safety on the highways by reducing both the number and severity of accidents (Villasenor, 2014; Szalay et al., 2018).

\section{Methodology}

Cross-sectional, descriptive research was the underlying methodology of this study. Specifically, correlational research design was selected because, after data analysis, the relationships between constructs were described using this approach (Lappe, 2000).

\subsection{Research questions}

The following research questions (RQ) were framed for this study:

RQ1: Is there a relationship between social influence and the intention to use AV?

RQ2: Is there a relationship between technophobia and the intention to use AV?

RQ3: Is there a relationship between the perceived safety of AVT and the intention to use AV?

RQ4: Is there a relationship between the number of automobile-related accidents and the intention to use AV?

RQ5: Do the demographic variables (Age, Gender, Annual Household Income and Level of Education) moderate the relationship between social influence and the intention to use AV?

RQ6: Do the demographic variables (Age, Gender, Annual Household Income, and Level of Education) moderate the relationship between technophobia and the intention to use AV?

RQ7: Do the demographic variables (Age, Gender, Annual Household Income, and Level of Education) moderate the relationship between perceived safety of AVT and the intention to use AV?

RQ8: What is the combined impact of social influence, technophobia, perceived safety of AVT, and the number of automobile-related accidents on the intention to use AV?

\subsection{Population and sample}

The employees of a particular tier one automotive accessory manufacturer, which has 13 sister divisions located across the United States $(\mathrm{N}=2,346)$, were the population of this study. Because different divisions represent strata with unequal size, proportional stratified sampling was used for the sample selection. A total of 1,173 people received the request via email to participate in this study. 


\subsection{Instrument}

The study instrument included adapted versions of existing instruments as presented in the Table 1.

Likert-type scale with five scale points and five anchors was used to measure each construct. As shown in Table 2, the criteria of Cronbach's $\alpha>0.7$ was used to confirm the scale's internal consistency.

\subsection{Data collection}

The targeted usable survey were 200-300 responses, with a sufficient diversification of genders, age groups, education levels, ethnic heritage, and annual household income. Data for this research study was collected via an online survey. The study instrument as a Survey Monkey link was distributed via an email to the sample situated across the U.S. For background information, the respondents watched a brief video on AVT before completing the instrument.

Before the survey was closed, 567 responses were received. The raw data was then observed for any missing values, and 44 responses were found to be incomplete. Eight respondents did not meet the criteria of having a valid U.S. driver's license, 82 respondents answered the dummy questions incorrectly, and six respondents answered with a same ranking pattern and within less than four minutes. Univariate and bivariate outlier tests further reduced the data by 50 responses. The final sample $(n=377)$ was $16 \%$ of the population $(\mathrm{N})$. The majority of sample reflected a diverse job function background with $6.4 \%$ as executive management, $6.9 \%$ as marketing, $13.0 \%$ as sales, $11.4 \%$ as customer service, $7.4 \%$ as finance/accounting, $10.9 \%$ as engineering, and $9.3 \%$ as general management.

Table 1 Items used on the study instrument

\begin{tabular}{|c|c|}
\hline Constructs & Items \\
\hline $\begin{array}{l}\text { Intention to use } \\
\mathrm{AV}\end{array}$ & $\begin{array}{l}\text { Adapted from Nees (2016:p.1452) } \\
\text { 1. Given that I would have access to an autonomous vehicle, I foresee that I would use it. } \\
\text { 2. I intend to own an autonomous vehicle when they become available in the market. } \\
\text { 3. I intend to add an autonomous vehicle on the list of my favorite cars. }\end{array}$ \\
\hline Social Influence & $\begin{array}{l}\text { Adapted from Venkatesh et al. (2003:p.460) } \\
\text { 1. People that I respect may think that I should make use of an autonomous vehicle. } \\
\text { 2. People who are important to me may influence my decision about using an autonomous vehicle. } \\
\text { 3. People whose opinion I value may influence my choice of purchasing an autonomous vehicle. } \\
\text { 4. People who influence my behavior may think that I should use an autonomous vehicle. }\end{array}$ \\
\hline Technophobia & $\begin{array}{l}\text { Adapted from Khasawneh (2015) p.145 } \\
\text { 1. I am fearful that someone is using technology to watch and listen to everything that I do. } \\
\text { 2. I am terrified that technologies will change the way we live, communicate, love, and even judge others. } \\
\text { 3. I am afraid of new technologies because one day it will make us (humans) obsolete. } \\
\text { 4. I am fearful that new technologies will someday take over my job. } \\
\text { 5. I am afraid to eat genetically modified food. } \\
\text { 6. I feel restless when I have to use a new communication device. } \\
\text { 7. I feel restless when I have to learn a new computer operating system (For example, changing from Windows } 7 \text { to Windows } 8 \text { ). } \\
\text { 8. I am afraid that technology will take over my personal life (and I will lose my sense of reality). } \\
\text { 9. I am afraid of new technologies because if something goes wrong with it (if it stopped working for some reason) we will go } \\
\text { back to the Stone Age. } \\
\text { 10. I am afraid of using search engines such as Google. } \\
\text { 11. I feel anxious every time I use a new program. } \\
\text { 12. I am terrified of being connected to the internet, someone might be tracking me. } \\
\text { 13. I am fearful that robots may take over the world. } \\
\text { 14. I am afraid of websites such as Google, Yahoo, and Bing because they make it very easy for people to stalk me. }\end{array}$ \\
\hline $\begin{array}{l}\text { Perceived Safety } \\
\text { of AVT }\end{array}$ & $\begin{array}{l}\text { Adapted from Casley et al. (2013) p. } 32 \\
\text { 1. I would trust that a computer in an autonomous vehicle could get me to my destination safely with no assistance from me. } \\
\text { 2. I believe an autonomous vehicle would be safer to drive on populated streets when compared to the average human driver. } \\
\text { 3. I would be comfortable entrusting the safety of a close family member riding in an autonomous vehicle. } \\
\text { 4. I believe an autonomous vehicle would be safer to drive on expressways and highways compared to the average human driver. }\end{array}$ \\
\hline $\begin{array}{l}\text { Socio-Economic } \\
\text { Demographic } \\
\text { Variables }\end{array}$ & $\begin{array}{l}\text { 1. Age } \\
\text { 2. Gender } \\
\text { 3. Annual Household income } \\
\text { 4. Ethnicity } \\
\text { 5. Level of education } \\
\text { 6. Job function } \\
\text { 7. Number of automobile-related accidents in last three years }\end{array}$ \\
\hline
\end{tabular}


Table 2 Reliability Analysis of the Study Instrument

\begin{tabular}{lcc}
\hline Constructs & Cronbach's $\alpha$ & Number of Items \\
\hline Intention to use AV & 0.902 & 3 \\
Social influence & 0.794 & 4 \\
Technophobia & 0.803 & 14 \\
Perceived Safety of AVT & 0.904 & 4 \\
\hline
\end{tabular}

\section{Analysis and results}

After the demographic analysis, we utilized inferential statistical procedures to determine the relationship between social influence, technophobia, perceived safety of AVT, the number of automobile-related accidents, and the intention to adopt AVT. The Statistical Package for the Social Sciences (SPSS) version 24.0 was used as a tool for performing the various statistical procedures as shown in Table 3.

A preliminary analysis to check for any assumption violations revealed that the data reasonably met the assumptions of Pearson's correlation and multiple linear regression.

\subsection{Demographic results}

Age. Out of 377 samples included in this study, the majority of age distribution was as follows: 67 (17.8\%) were between the ages of 25-30, 38 (10.1\%) were between the ages of 31-34, 59 (15.6\%) were between the ages of 35-40, $98(26.0 \%)$ were between the ages of 41-50, and finally 60 (15.9\%) were between the ages of 51-60.

For moderation analysis, the variable of age was recoded into three groups. Group one (18-34, representing young people), group two (35-50, representing middle aged people), and finally group three (51+, representing older people).

Gender. For gender distribution, 258 (68.4\%) were male participants, and 119 (31.6\%) were female participants.

Annual household income. The majority of annual household income distribution was as follows: 64 (17.0\%) reported making between $\$ 25,000-\$ 49,999 ; 72$ (19.1\%) between $\$ 50,000-\$ 74,999 ; 82$ (21.8\%) between $\$ 75,000$ $\$ 99,999$; and 65 (17.2\%) between \$100,000-\$124,999.

For moderation analysis, the annual household income variable was recoded into three groups. Group one (representing low-income households, $<\$ 75 \mathrm{k}$ ), group two (representing medium income households, \$75k - 125k), and finally group three (representing high-income households, $\$ 125 \mathrm{k}+$ ).

Ethnicity. The majority of the sample $328(87.0 \%)$ answered White / Caucasian as their ethnicity.
Table 3 Data Analysis Approach

\begin{tabular}{lc}
\hline Research & Inferential Statistical Techniques \\
\hline RQ1 & Pearson Correlation \\
RQ2 & Pearson Correlation \\
RQ3 & Pearson Correlation \\
RQ4 & Pearson Correlation \\
RQ5 & Pearson Correlation \\
RQ6 & Pearson Correlation \\
RQ7 & Pearson Correlation \\
RQ8 & Multiple Linear Regression \\
\hline
\end{tabular}

Level of education. The majority of education level distribution was as follows: 43 (11.4\%) answered high school, 103 (27.3\%) responded some college, but no degree, 37 $(9.8 \%)$ indicated associate degree, 144 (38.2\%) reported bachelor degree, and 33 (8.8\%) stated graduate degree as their current highest level of education.

For moderation analysis, the level of education variable was recoded into two groups. Group one (representing low education, less than bachelor's degree), and group two (representing high education, bachelor's degree or higher).

\subsection{Findings of research questions}

The Pearson's Correlations between Social Influence, Technophobia, Perceived Safety of AVT, Number of Automobile-Related Accidents and the Intention to use AV are shown in Table 4.

The followings provide the analysis of each research question:

$R Q 1$. Social influence and the intention to use AV had a moderate, positive relationship $(r=0.454, n=377$, $p<0.001)$. Also, this relationship was found to be statistically significant.

$R Q 2$. Technophobia and the intention to use AV had a weak, negative relationship $(r=-0.124, n=377$, $p<0.05)$. Also, this relationship was found to be statistically significant.

Table 4 Pearson Correlations

\begin{tabular}{lc}
\hline & Intention to Use AV \\
\hline Social Influence & $0.454 * * *$ \\
Technophobia & $-0.124 *$ \\
Perceived Safety of AVT & $0.687 * * *$ \\
Number of Automobile-Related Accidents & $0.059 \dagger$ \\
\hline Note: $\dagger=\mathrm{p}<0.10, *=\mathrm{p}<0.05, * *=\mathrm{p}<0.01, * * *=\mathrm{p}<0.001 . \mathrm{N}=377$ \\
for all analyses.
\end{tabular}


Table 5 Multiple Regression Model Summary for RQ8

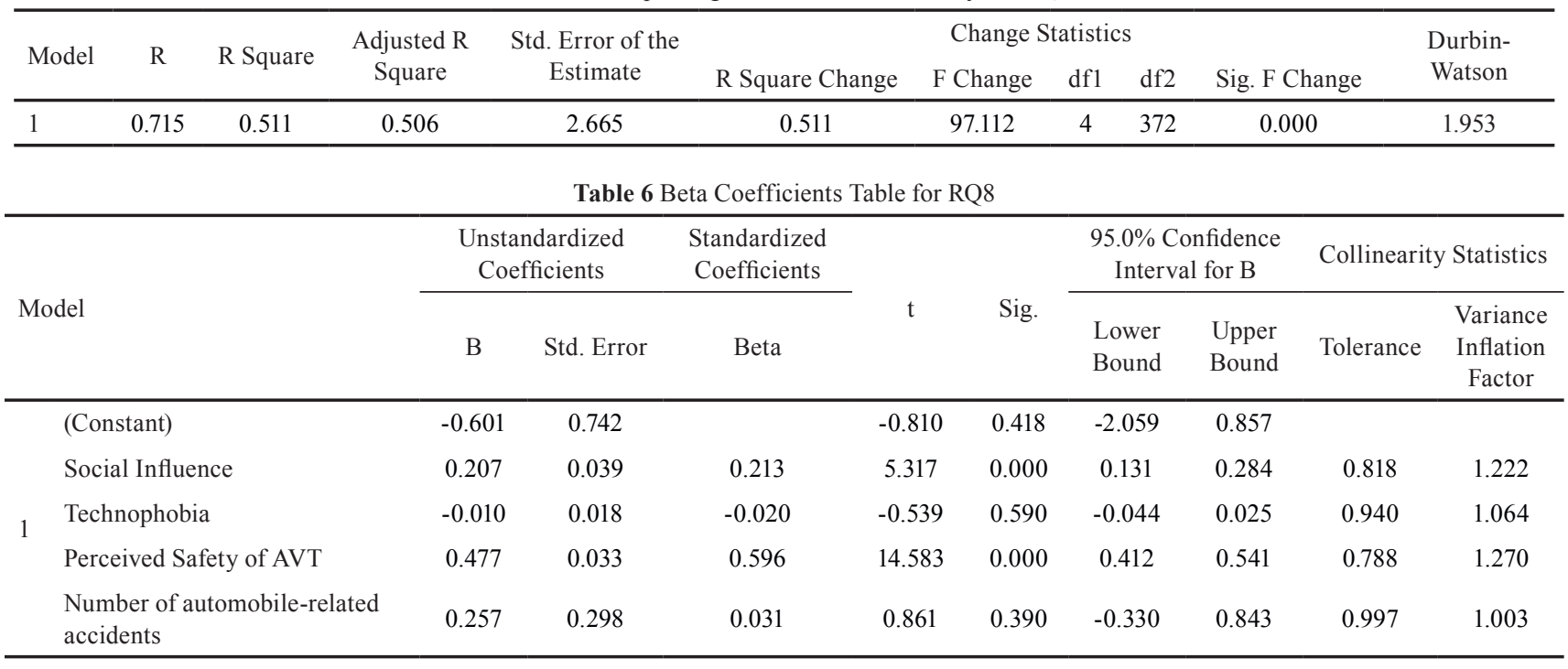

Table 7 Results of Research Questions

RQ1 Is there a relationship between social influence and the intention to use AV?

RQ2 Is there a relationship between technophobia and the intention to use AV?

RQ3 Is there a relationship between the perceived safety of AVT and the intention to use AV?

RQ4 Is there a relationship between the number of automobile-related accidents and the intention to use AV?

RQ5 Do the demographic variables (Age, Gender, Annual Household Income and Level of Education) moderate the relationship between social influence and the intention to use AV?

RQ6 Do the demographic variables (Age, Gender, Annual Household Income, and Level of Education) moderate the relationship between technophobia and the intention to use AV?

RQ7 Do the demographic variables (Age, Gender, Annual Household Income, and Level of Education) moderate the relationship between perceived safety of AVT and the intention to use AV?

RQ8 What is the combined impact of social influence, technophobia, perceived safety of AVT, and the number of automobile-related accidents on the intention to use AV?
It was shown that the increase in perceived social pressure generated via social forces prompted moderate increase in the intention to use AV.

It was found that as the perceptual response of fear and anxiety towards AVT increases, the intentions of consumers to use AV decreases slightly.

This was the strongest correlation found in this study. The perceived safety construct may serve as a significant focus area for the marketers of AVT.

The data showed that there is no relationship between the number of automobile-related accidents and the intentions to use AV.

The correlation between social influence and the intention to use $\mathrm{AV}$ was relatively higher for younger people than for older people.

Older people appeared to be more technophobic than the younger population. Therefore, increased technophobia in older people was associated with a further decrease in the intention to use AV.

People with low income appeared to be more technophobic, which may be related to their financial status resulting in limited familiarity with various new technologies, as compared to those with higher income. Therefore, increased technophobia in people with low annual household income appeared to be associated with a further decrease in the intentions to use AV.

Females appeared to set a higher emphasis on safety over males. Therefore, an increased need for safety within females may be leading to a relatively higher correlation between the perceived safety of AVT and the intention to use AV.

With the exceptions of technophobia and the number of automobile-related accidents, both social influence and perceived safety of AVT were significant predictors of intention to use AV.
$R Q 3$. The perceived safety of AVT and the intention to use AV had a strong, positive relationship ( $r=$ $0.687, n=377, p<0.001)$. Also, this relationship was found to be statistically significant.

$R Q 4$. The number of automobile-related accidents and the intention to use AV did not have a statistically significant relationship ( $r=0.059, n=377, p<0.10$ ).

$R Q 5$. Age was found to moderate the relationship between social influence and the intention to use AV. However, gender, annual household income, 
and level of education did not moderate this relationship. The correlation coefficient values when moderating with three categories of the age variable were: Young people: $(\mathrm{r}=0.518, \mathrm{n}=138, \mathrm{p}<0.001)$, Middle aged people: $(\mathrm{r}=0.467, \mathrm{n}=157, \mathrm{p}<0.001)$, and Older people: $(\mathrm{r}=0.323, \mathrm{n}=82, \mathrm{p}<0.01)$.

RQ6. Age and annual household income were found to moderate the relationship between technophobia and the intention to use AV. However, gender and level of education were not found to moderate this relationship. The correlation coefficient values when moderating with different categories of the age variables were: Young people: $(r=-0.118, n=$ $138, \mathrm{p}>0.05)$, Middle aged people: $(\mathrm{r}=0.002, \mathrm{n}=$ $157, \mathrm{p}>0.05)$, and Older people: $(\mathrm{r}=-0.330, \mathrm{n}=82$, $\mathrm{p}<0.01)$. The correlation coefficient values when moderating with different categories of the annual household income variables were: Low: $(r=-0.202$, $\mathrm{n}=148, \mathrm{p}<0.05)$, Medium: $(\mathrm{r}=-0.068, \mathrm{n}=147, \mathrm{p}>$ $0.05)$, and High: $(\mathrm{r}=-0.055, \mathrm{n}=82, \mathrm{p}>0.05)$.

$R Q 7$. Gender and annual household income were found to moderate the relationship among the perceived safety of AVT and the intention to use AV. However, age and level of education did not moderate this relationship. The correlation coefficient values when moderating with different categories of the gender variables were: Male: $(\mathrm{r}=0.658, \mathrm{n}=$ 258, $\mathrm{p}<0.001)$ and Female: $(\mathrm{r}=0.765, \mathrm{n}=119, \mathrm{p}$ $<0.001)$. The correlation coefficient values when moderating with different categories of annual household income variables were: Low: $(r=0.660$, $\mathrm{n}=148, \mathrm{p}<0.001)$, Medium: $(\mathrm{r}=0.659, \mathrm{n}=147, \mathrm{p}$ $<0.001)$, and High: $(\mathrm{r}=0.796, \mathrm{n}=82, \mathrm{p}<0.001)$.

$R Q 8$. The regression model adequately explained variance in the intention to use $\mathrm{AV}\left(R^{2}=0.506, n=377\right.$, $p<0.001)$. Also, the model was statistically significant as the significance threshold was set at $\mathrm{p} \leq 0.05$.

By analysing the regression coefficient of $\mathrm{R}^{2}=0.506$, we formulated a statistical explanation that $50.6 \%$ of the variance in the intention to use AV is explained by the combination of social influence and perceived safety of AVT. The regression model summary and beta coefficients table for RQ8 are shown in Table 5 and Table 6, respectively.

The significant beta values $(\mathrm{B}$ - Social Influence $=$ 0.207 and B - Perceived Safety of AVT $=0.477$ ) reflect the step change in a consumer's intention to use AV for each corresponding increment change in social influence and perceived safety of AVT, respectively. However, the beta values for technophobia and the number of automobile-related accidents were not statistically significant, and therefore, could not predict a person's intention to use AV. The findings of reserch questions are summerized in Table 7.

\subsection{Limitations}

This study was limited to determination of current consumers' acceptance of AVT, which may change in the future depending upon the technology itself, and to the fully automated driverless product category, which its generalization to other autonomous car categories may not be possible. Also, the majority of respondents had white caucasian ethnicity.

\subsection{Comparative analysis}

This study found that increases in perceived social pressure generated by social forces prompts moderate increase in the intention to use AV. This finding supports the existing research that the construct of social influence is a significant determinant of behavioural intentions across various settings (Agarwal, 2000; Ajzen and Driver, 1992; Bamberg et al., 2003; George, 2004; Godin and Kok, 1996; Parker et al., 1992; Pavlou and Fygenson, 2006; Shih and Fang, 2004; Taylor and Todd, 1995; Venkatesh et al., 2007). Social Influence may have a high degree of importance for AVT adoption, given that, if social influence is negative, the predictions made by other relational factors of AVT adoption could be undermined.

It was found that the intentions of consumers to use AV decreases slightly as the perceptual response of fear and anxiety towards AVT increases. This finding supports innovation adoption literature that the construct of technophobia is negatively correlated with new technology acceptance (Khasawneh, 2015; Sinkovics et al., 2002). The respondents may have had decreased techno-fear and anxiety, and perhaps had not observed the technophobia construct to be critical relative to the other relational constructs of intentions to use AV.

The findings indicated as the viewpoint of the safety associated with AVT strengthens, the intentions to use AV strongly increases. This finding supports the existing research that the construct of the perceived safety of AVT is a significant factor impacting consumers' intention to use AV (Bansal et al., 2016; Casley et al., 2013).

Due to the strongest correlation within this study, the perceived safety construct may serve as a significant focus area for the marketers of AVT. The consumer belief that AVT will 
enhance the safety of its passengers and the surroundings may lead to developing the trust and confidence required for the adoption of AVT (Bansal et al., 2016; Cao et al., 2016).

Younger people appeared to be more inclined towards internalizing societal influences, which ultimately strengthened the correlation in their case. On the other hand, older people appeared to be less affected by social influences. This finding supports the existing literature examining the relationship between social influence and behavioral intentions (Venkatesh et al., 2003).

It was shown that increased technophobia in older people was associated with a further decrease in the intention to use AV. This finding supports the existing literature examining the relationship between technophobia and innovation adoption (Gilbert et al., 2003).

The correlation was higher for people with a high annual household income when compared with other income categories. People with higher annual household income may have a belief of relatively higher liability with AVT adoption compared to people in other income categories. Therefore, people with higher annual household income presented a relatively stronger relationship between the perceived safety of AVT and the intention to use AV.

\section{References}

Agarwal, R. (2000) "Individual acceptance of information technologies", In: Zmud, R. W. (ed.) Framing the domains of IT management: Projecting the future through the past, Pinnaflex Education Resources, Inc. Cincinti, Ohio, USA, pp. 85-104.

Ajzen, I. (1985) "From intentions to actions: A Theory of Planned Behavior", In: Kuhl. J. (ed.) Action control, Springer Berlin, Heidelberg, Germany, pp. 11-39. https://doi.org/10.1007/978-3-642-69746-3_2

Ajzen, I. (1991) "The Theory of Planned Behavior", Organizational Behavior and Human Decision Processes, 50(2), pp. 179-211. https://doi.org/10.1016/0749-5978(91)90020-T

Ajzen, I., Driver, B. L. (1992) "Application of the Theory of Planned Behavior to leisure choice", Journal of Leisure Research, 24(3), pp. 207-224.

https://doi.org/10.1080/00222216.1992.11969889

Ajzen, I., Fishbein, M. (2010) "Constructing a reasoned action questionnaire", In: Predicting and changing behaviour: The reasoned action approach, Psychology Press, New York, NY, USA, pp. 449-464. [online] Available at: http://people.umass.edu/ aizen/pdf/tpb.measurement.pd [Accessed: 23 February 2017]

Bamberg, S., Ajzen, I., Schmidt, P. (2003) "Choice of travel mode in the Theory of Planned Behavior: The roles of past behaviour, habit, and reasoned action", Basic and Applied Social Psychology, 25(3), pp. $175-187$.

https://doi.org/10.1207/S15324834BASP2503 01

\section{Conclusions}

In this paper, the initial set of predictors capable of explaining AVT adoption by providing bivariate and multivariate analysis that is critical for the early adoption of this technology was presented. Data provided can be used to remove the implementation barriers of AVT adoption, by focusing on the areas found to be more resistant to AVT adoption. Planning officials may find the results useful for their internal planning analysis.

This study revealed that AVT manufacturers have to design and implement interventions to reduce the technophobia of the senior population. As the older population is expected to account for a significant amount of the population in the U.S., it becomes critical to further study technophobia associated AVT adoption.

It is recommended that the moderating effects of technophobia on the relationship between perceived safety of AVT and intention to use AV be included in future studies. Also, the interaction between the dimension of self-awareness and social influence such as "Are consumers realistically self-aware enough to detect any external societal influence?" and the uncertainty of whether "consumers are willing to admit they are as influenced by others as they are" remain to be explored as well.

Bansal, P., Kockelman, K. M., Singh, A. (2016) "Assessing public opinions of and interest in new vehicle technologies: An Austin perspective", Transportation Research Part C: Emerging Technologies, 67, pp. 1-14. https://doi.org/10.1016/j.trc.2016.01.019

Bansal, P., Kockelman, K. M. (2017) "Forecasting Americans' long-term adoption of connected and autonomous vehicle technologies", Transportation Research Part A: Policy and Practice, 95, pp. 49-63. https://doi.org/https://doi.org/10.1016/j.tra.2016.10.013

Brett, J. A. (2016) "Thinking local about self-driving cars: A local framework for autonomous vehicle development in the United States", MSc Thesis, University of Washington.

Cao, H., Song, X., Huang, Z., Pan, L. (2016) "Simulation research on emergency path planning of an active collision avoidance system combined with longitudinal control for an autonomous vehicle", Proceedings of the Institution of Mechanical Engineers, Part D: Journal of Automobile Engineering, 230(12), pp. 1624-1653. https://doi.org/10.1177/0954407015618533

Casley, S. V., Jardim, A. S., Quartulli, A. M. (2013) "A study of public acceptance of autonomous cars", Worcester Polytechnic Institute, Massachusetts, United States, p. 156. [online] Available at: https:// digitalcommons.wpi.edu/iqp-all/2596 [Accessed: 13 March 2017] 
Celaya, L. A. (1996) "The relationship between technophobia among the manufacturing workforce and the age and gender of selected workers", PhD Thesis, Walden University, USA. [online] Available at: http://search.proquest.com/docview/304343856/abstract/4DAV2E92541C4225PQ/ [Accessed: 15 April 2017]

Chen, C. (2016) "Extracting cognition out of images for the purpose of autonomous driving", PhD Thesis, Princeton University, USA. [online] Available at: http://search.proquest.com/pqdtglobal/docview/1805918934/abstract/D74E736B56B840B8PQ/9 [Accessed: 21 January 2017]

Creaser, J. I. (2004) "Training young drivers: The effect of verbal and eventbased feedback on drivers' following behaviorand confidence", MSc Thesis, University of Calgary, Canada. [online] Available at: http://search.proquest.com/pqdtglobal/docview/305224241/abstract/ A917E384D9084CC1PQ/6 [Accessed: 21 January 2017]

Dorn, L. (1992) "Individual and group differences in driving behaviour", $\mathrm{PhD}$ Thesis, Aston University, UK. [online] Available at: http://search.proquest.com/pqdtglobal/docview/301538250/ A917E384D9084CC1PQ/4 [Accessed: 21 January 2017]

Fagnant, D. J., Kockelman, K. (2015) "Preparing a nation for autonomous vehicles: Opportunities, barriers and policy recommendations", Transportation Research Part A: Policy and Practice, 77, pp. 167-181. https://doi.org/10.1016/j.tra.2015.04.003

Gadepally, V. N. (2013) "Estimation of driver behaviorfor autonomous vehicle applications", PhD Thesis, The Ohio State University, USA. [online] Available at: http://search.proquest.com/pqdtglobal/docview/1647127404/abstract/D74E736B56B840B8PQ/11 [Accessed: 21 January 2017]

George, J. F. (2004) "The Theory of Planned Behavior and internet purchasing", Internet Research, 14(3), pp. 198-212. https://doi.org/10.1108/10662240410542634

Gilbert, D., Kelley, L., Barton, M. (2003) "Technophobia, gender influences and consumer decision making for technology related products", European Journal of Innovation Management, 6(4), pp. 253-263.

https://doi.org/10.1108/14601060310500968

Godin, G., Kok, G. (1996). "The Theory of Planned Behavior: A review of its applications to health-related behaviours", American Journal of Health Promotion, 11(2), 87-98.

https://doi.org/10.4278/0890-1171-11.2.87

Guerra, E. (2016) "Planning for cars that drive themselves: Metropolitan planning organizations, regional transportation plans, and autonomous vehicles", Journal of Planning Education and Research, 36(2), pp. 210-224.

https://doi.org/10.1177/0739456X15613591

Heide, A., Henning, K. (2006) "The "cognitive car": A roadmap for research issues in the automotive sector", Annual Reviews in Control, 30(2), pp. 197-203.

https://doi.org/10.1016/j.arcontrol.2006.09.005

Holden, R. J., Karsh, B. T. (2010) "The Technology Acceptance Model: Its past and its future in health care", Journal of Biomedical Informatics, 43(1), pp. 159-172. https://doi.org/10.1016/j.jbi.2009.07.002
Khasawneh, O. (2015) "The impact of technophobia on technology acceptance and the moderating influence of transformational leadership, organizational climate, and emotional intelligence", PhD Thesis, Eastern Michigan University, USA. [online] Available at: https://www.researchgate.net/publication/322730450_The Impact_of_Technophobia_on_Technology_Acceptance_and the_Mo [Accessed: 14 April 2017]

Kulviwat, S., Bruner, G. C., Al-Shuridah, O. (2009) "The role of social influence on adoption of high tech innovations: The moderating effect of public/private consumption", Journal of Business Research, 62(7), pp. 706-712.

https://doi.org/10.1016/j.jbusres.2007.04.014

Lam, A. Y. S., Leung, Y. W., Chu, X. (2016) "Autonomous-vehicle public transportation system: Scheduling and admission control", IEEE Transactions on Intelligent Transportation Systems, 17(5), pp. $1210-1226$.

https://doi.org/10.1109/TITS.2015.2513071

Lappe, J. M. (2000) "Taking the mystery out of research: Descriptive correlational design", Orthopaedic Nursing, 19(2), p. 81. [online] Available at: http://hdl.handle.net/10504/72007 [Accessed: 11 March 2017]

Lee, Y., Kozar, K. A., Larsen, K. R. (2003) "The Technology Acceptance Model: Past, present, and future", Communications of the Association for Information Systems, 12, Article 50. https://doi.org/10.17705/1CAIS.01250

Li, L. (2010) "A critical review of technology acceptance literature", Grambling State University, USA. [online] Available at: http:// www.swdsi.org/swdsi2010/sw2010_preceedings/papers/pa104.pdf [Accessed: 26 February 2017]

Litman, T. (2014) "Autonomous vehicle implementation predictions", Victoria Transport Policy Institute, p. 39. [online] Available at: http://www.vtpi.org/avip.pdf [Accessed: 12 February 2017]

Lu, J., Yao, J. E., Yu, C. S. (2005) "Personal innovativeness, social influences and adoption of wireless internet services via mobile technology", The Journal of Strategic Information Systems, 14(3), pp. $245-268$. https://doi.org/10.1016/j.jsis.2005.07.003

Mathieson, K. (1991) "Predicting user intentions: Comparing the Technology Acceptance Model with the Theory of Planned Behavior", Information Systems Research, 2(3), pp. 173-191. https://doi.org/10.1287/isre.2.3.173

Menon, N. (2015) "Consumer perception and anticipated adoption of autonomous vehicle technology: Results from multi-population surveys", MSc Thesis, University of South Florida, USA. [online] Available at: https://scholarcommons.usf.edu/etd/5992/ [Accessed: 21 January 2017]

Nees, M. A. (2016) "Acceptance of self-driving cars: An examination of idealized versus realistic portrayals with a self-driving car acceptance scale", Proceedings of the Human Factors and Ergonomics Society Annual Meeting, 60(1), pp. 1449-1453. https://doi.org/10.1177/1541931213601332

NHTSA (2013) "Preliminary statement of policy concerning automated vehicles". [online] Available at: https://www.nhtsa.gov/staticfiles/ rulemaking/pdf/Automated_Vehicles_Policy.pdf [Accessed: 26 March 2017] 
NHTSA (2016) "Traffic safety facts: Early estimate of motor vehicle traffic fatalities for the first 9 months of 2016", (Rep. DOT HS 812 358). [online] Available at: https://crashstats.nhtsa.dot.gov/Api/ Public/Publication/812358 [Accessed: 26 March 2017]

Parker, D., Manstead, A. S., Stradling, S. G., Reason, J. T., Baxter, J. S. (1992) "Intention to commit driving violations: An application of the Theory of Planned Behavior", Journal of Applied Psychology, 77(1), pp. 94-101. https://doi.org/10.1037/0021-9010.77.1.94

Pavlou, P. A., Fygenson, M. (2006) "Understanding and predicting electronic commerce adoption: An extension of the Theory of Planned Behavior", MIS Quarterly, 30(1), pp. 115-143. [online] Available at: https://www.jstor.org/stable/25148720 [Accessed: 23 February2017]

Payre, W., Cestac, J., Delhomme, P. (2014) "Intention to use a fully automated car: Attitudes and a priori acceptability", Transportation Research Part F: Traffic Psychology and Behaviour, 27, pp. 252-263. https://doi.org/10.1016/j.trf.2014.04.009

Shih, Y., Fang, K. (2004) "The use of a decomposed Theory of Planned Behavior to study internet banking in Taiwan", Internet Research, 14(3), pp. 213-223. https://doi.org/10.1108/10662240410542643

Sinkovics, R. R., Stöttinger, B., Schlegelmilch, B. B., Ram, S. (2002) "Reluctance to use technology-related products: Development of a technophobia scale", Thunderbird International Business Review, 44(4), pp. 477-494. https://doi.org/10.1002/tie.10033

Talebpour, A., Mahmassani, H. S. (2016) "Influence of connected and autonomous vehicles on traffic flow stability and throughput", Transportation Research Part C: Emerging Technologies, 71, pp. $143-163$ https://doi.org/10.1016/j.trc.2016.07.007

Taylor, S., Todd, P. (1995) "Decomposition and crossover effects in the Theory of Planned Behavior: A study of consumer adoption intentions", International Journal of Research in Marketing, 12(2), pp. 137-155.

https://doi.org/10.1016/0167-8116(94)00019-K
Tettamanti, T., Varga, I., Szalay, Z. (2016) "Impacts of Autonomous Cars from a Traffic Engineering Perspective", Periodica Polytechnica Transportation Engineering, 44(4), pp. 244-250. https://doi.org/10.3311/PPtr.9464

Venkatesh, V., Davis, F. D., Morris, M. G. (2007) "Dead or alive? The development, trajectory and future of technology adoption research", Journal of the Association for Information Systems, 8(4), pp. 267-287. https://aisel.aisnet.org/jais/vol8/iss4/10

Venkatesh, V., Morris, M. G., Davis, G. B., Davis, F. D. (2003) "User acceptance of information technology: Toward a unified view", MIS Quarterly, 27(3), pp. 425-478. https://doi.org/10.2307/30036540

Villasenor, J. (2014) "Products Liability and Driverless Cars: Issues and Guiding Principles for Legislation". [online] Available at: https://www.brookings.edu/research/products-liability-and-driverless-cars-issues-and-guiding-principles-for-legislation/ [Accessed: 23 February 2017]

Yibing, Z., Hongbin, X., Lie, G., Linhui, L., Mingheng, Z. (2014) "Research of obstacle recognition technology in cross-country environment for unmanned ground vehicle", Mathematical Problems in Engineering, 2014, Article ID: 531681, p. 13. https://doi.org/10.1155/2014/531681

Szalay, Z., Tettamanti, T., Esztergár-Kiss, D., Varga, I. Bartolini, C. (2018) "Development of a Test Track for Driverless Cars: Vehicle Design, Track Configuration, and Liability Considerations", Periodica Polytechnica Transportation Engineering, 46(1), pp. 29-35.

https://doi.org/10.3311/PPtr.10753 